\title{
Spatial Correlations and Distribution of Competence Gene Expression in Biofilms of Streptococcus mutans
}

\author{
Ivan P. Ishkov', Justin R. Kaspar'2t and Stephen J. Hagen ${ }^{1 *}$ \\ 1 Department of Physics, University of Florida, Gainesville, FL, United States, ${ }^{2}$ Department of Oral Biology, College \\ of Dentistry, University of Florida, Gainesville, FL, United States
}

OPEN ACCESS

Edited by:

Peter Graumann,

University of Marburg, Germany

Reviewed by:

Marlise Inez Klein,

São Paulo State University, Brazil

Saswat S. Mohapatra,

Khallikote University, India

*Correspondence:

Stephen J. Hagen

sjhagen@ufl.edu

${ }^{\text {t}}$ Present address:

Justin R. Kaspar,

Division of Biosciences, College of Dentistry, Ohio State University,

Columbus, $\mathrm{OH}$, United States

Specialty section:

This article was submitted to Microbial Physiology and Metabolism,

a section of the journal

Frontiers in Microbiology

Received: 10 November 2020

Accepted: 17 December 2020

Published: 12 January 2021

Citation:

Ishkov IP, Kaspar JR and Hagen SJ (2021) Spatial Correlations and Distribution of Competence Gene Expression in Biofilms

of Streptococcus mutans.

Front. Microbiol. 11:627992. doi: 10.3389/fmicb.2020.627992
Streptococcus mutans is an important pathogen in the human oral biofilm. It expresses virulent behaviors that are linked to its genetic competence regulon, which is controlled by $\operatorname{com} X$. Expression of $\operatorname{com} X$ is modulated by two diffusible signaling peptides, denoted CSP and XIP, and by other environmental cues such as $\mathrm{pH}$ and oxidative stress. The sensitivity of $S$. mutans competence to environmental inputs that may vary on microscopic length scales raises the question of whether the biofilm environment creates microniches where competence and related phenotypes are concentrated, leading to spatial clustering of $S$. mutans virulence behaviors. We have used twophoton microscopy to characterize the spatial distribution of comX expression among individual S. mutans cells in biofilms. By analyzing correlations in comX activity, we test for spatial clustering that may suggest localized competence microenvironments. Our data indicate that both competence-signaling peptides diffuse efficiently through the biofilm. XIP elicits a population-wide response. CSP triggers a Poisson-like, spatially random com $X$ response from a subpopulation of cells that is homogeneously dispersed. Our data indicate that competence microenvironments if they exist are small enough that the phenotypes of individual cells are not clustered or correlated to any greater extent than occurs in planktonic cultures.

Keywords: Streptococcus mutans, bimodality, fluorescence, biofilm, confocal, multi-photon, comX, quorum sensing

\section{INTRODUCTION}

Oral biofilms are complex microbial communities that may be inhabited by pathogenic as well as commensal species. As a primary etiological agent of dental caries in humans, Streptococcus mutans is an important biofilm pathogen (Loesche, 1986; Takahashi and Nyvad, 2011). It forms thick and densely clustered biofilms, especially in the presence of sucrose (Kreth et al., 2004; Leme et al., 2006), consisting of cell clusters embedded in a matrix of insoluble exopolysaccharides, extracellular DNA and other secretions (Watnick and Kolter, 2000; Branda et al., 2005; Xiao and Koo, 2010; Koo et al., 2013). The resulting biofilm is chemically and physically heterogeneous, with parameters such as $\mathrm{pH}$ and oxygen concentration varying on microscopic length scales. For example, $S$. mutans fermentation of carbohydrates from the host diet gives rise to localized microenvironments of reduced $\mathrm{pH}$ in the oral biofilm (Bowen et al., 2018). At the tooth surface, these acidic niches promote dental caries by demineralizing the tooth enamel (Hunter and Beveridge, 2005; Leme et al., 2006; Takahashi and Nyvad, 2011; Guo et al., 2013; Koo et al., 2013). 
In addition to biofilm formation and acid production, the cariogenic behaviors of $S$. mutans include its acid tolerance, carbohydrate utilization, and production of bacteriocins. These behaviors are regulated in connection with the regulation of genetic competence, a transient physiological state in which the microbe can take up and incorporate exogenous DNA (Yoshida and Kuramitsu, 2002; Qi et al., 2004; Ahn et al., 2005, 2006; Senadheera et al., 2005, 2012; van der Ploeg, 2005; Kreth et al., 2006; Welin-Neilands and Svensäter, 2007). The competence pathway in $S$. mutans is sensitive to diffusible signaling peptides as well as to $\mathrm{pH}$, nutrient, and other environmental cues. Because these behaviors are strongly influenced by environmental inputs, one may anticipate that chemical microniches and restricted diffusion within the biofilm shape the spatial distribution of competence gene expression. This raises the question of how virulence behavior is distributed throughout a biofilm, and particularly whether expression is uniformly distributed, or is concentrated or localized into discrete, pathogenic microniches (Stewart, 2003; Parsek and Greenberg, 2005; Hense et al., 2007; Stewart and Franklin, 2008; Bowen et al., 2018).

In streptococci the competent state requires the expression of $\operatorname{comX}$ (also called sigX), which encodes an alternative sigma factor for the late competence genes (Cvitkovitch, 2001; Fontaine et al., 2015; Shanker and Federle, 2017). In S. mutans, the activation of $\operatorname{com} X$ is modulated by inputs such as $\mathrm{pH}$, oxidative stress, and the availability of carbohydrate and peptide nutrients. It is also controlled by two diffusible signaling peptides, denoted sigX inducing peptide (XIP) and competence stimulating peptide (CSP). XIP and CSP stimulate the ComRS transcriptional feedback loop through different mechanisms and therefore elicit qualitatively different responses from $\operatorname{com} X$ in a population of cells (Ahn et al., 2006; Ahn and Burne, 2007; Son et al., 2012, 2015; Guo et al., 2014; Moye et al., 2016; De Furio et al., 2017; Hagen and Son, 2017; Shanker and Federle, 2017).

CSP is produced from its precursor ComC, exported, and then cleaved to length 18 aa. Extracellular CSP interacts with the ComDE two-component system to drive expression of multiple genes associated with bacteriocin production and immunity. Through a mechanism that is not fully known, ComDE stimulates the ComRS system, which is the immediate regulator of $\operatorname{comX}$. ComR is an Rgg-like cytosolic regulator that interacts with the 7-residue XIP or its 17-residue precursor ComS to form a transcriptional activator for both coms and $\operatorname{comX}$ (MashburnWarren et al., 2010; Shanker and Federle, 2017; Underhill et al., 2019). When CSP is provided to the cell, the ComRS system functions as a noisy, intracellular transcriptional feedback loop. The loop can persist in either the ON (high ComS) or OFF (low ComS) state but is stimulated by CSP; exogenous CSP therefore triggers a subpopulation of cells (20-40\% in planktonic cultures) to switch $O N$ and activate $\operatorname{com} X$ while the rest of the population remains OFF (Ferrell, 2002; Son et al., 2012). Bimodal expression of $\operatorname{com} X$ is a signature property of stimulation by CSP.

By contrast, exogenous XIP can elicit a unimodal response from $\operatorname{com} X$ : Although the $\operatorname{com} X$ response to XIP varies from cell to cell, it occurs population-wide and is therefore qualitatively unlike the bimodal response to CSP. The unimodal response can be attributed to the import of extracellular XIP (through the
Opp permease), which directly interacts with ComR, bypassing the role of endogenous ComS/XIP in triggering the autofeedback loop. Owing to an interaction of growth media with the feedback loop, $\operatorname{comX}$ responds to XIP only in chemically defined media, whereas it responds to CSP only in complex growth media, rich in small peptides (Hagen and Son, 2017).

The important role of diffusible signals, as well as variables such as $\mathrm{pH}$ and oxygen concentration, raises the question of whether $\operatorname{comX}$ activity in biofilms of $S$. mutans is affected by limited diffusibility within the biofilm matrix, localized chemical gradients, or other physical/chemical factors that are heterogeneous at micron length scales. If activation of $\operatorname{comX}$ requires exchange of XIP or other signals that diffuse poorly through the matrix or are degraded in transit, then cells activating pathogenic behaviors linked to $\operatorname{com} X$ could exhibit some tendency to collocate or cluster (Parsek and Greenberg, 2005; Decho et al., 2010). Here we test this hypothesis using twophoton confocal microscopy to probe at single-cell resolution the expression of competence genes throughout the depth of $S$. mutans biofilms. By applying statistical tests derived from spatial ecology we assess the evidence for clustering vs. spatial randomness in $\operatorname{com} X$ active cells. Our data allow us to evaluate the diffusibility of the signaling peptides XIP and CSP and characterize the length scale of any microniches of competence activity.

\section{MATERIALS AND METHODS}

\section{Strains}

Table 1 shows the UA159-derived strains used in this study. To detect activation of $\operatorname{comX}$ in $S$. mutans biofilms, and to

TABLE 1 | Strains and plasmids used.

\begin{tabular}{|c|c|c|}
\hline Strain or plasmid & $\begin{array}{l}\text { Genotypes and/or } \\
\text { descriptions }\end{array}$ & $\begin{array}{l}\text { Source or } \\
\text { references }\end{array}$ \\
\hline \multicolumn{3}{|l|}{ S. mutans strains } \\
\hline UA159 & Wild-type & ATCC 700610 \\
\hline UA159/pDL278 & $\begin{array}{l}\text { Wild-type harboring an empty } \\
\text { plasmid pDL278, } \mathrm{Sp}^{r}\end{array}$ & Ishkov et al., 2020 \\
\hline UA159/P/dh-gfp & $\begin{array}{l}\text { UA159 harboring Pldh-gfp } \\
\text { promotor fusion on pDL278, Spr }\end{array}$ & Ishkov et al., 2020 \\
\hline $\begin{array}{l}\text { UA159/PcomX-gfp } \\
\text { (plasmid-based reporter) }\end{array}$ & $\begin{array}{l}\text { UA159 harboring PcomX-gfp } \\
\text { promoter fusion on pDL278, Spr }\end{array}$ & Son et al., 2012 \\
\hline $\begin{array}{l}\text { UA159/PcomX- } \\
\text { gfp/P23-rfp } \\
\text { (chromosomal } \\
\text { PcomX-gfp reporter) }\end{array}$ & $\begin{array}{l}\text { Chromosomally integrated } \\
\text { PcomX-gfp harboring a } \\
\text { P23-DsRed-Express2 red } \\
\text { fluorescent protein promotor } \\
\text { fusion on pDL278, } \mathrm{Sp}^{r}\end{array}$ & This Study \\
\hline UA159/Pxyl-gfp & $\begin{array}{l}\text { UA159 harboring Pxyl-gfp } \\
\text { promoter fusion on pZX9, Spr }\end{array}$ & Shields et al., 2020 \\
\hline \multicolumn{3}{|l|}{ Plasmid } \\
\hline pDL278 & $\begin{array}{l}\text { E. coli-Streptococcus shuttle } \\
\text { vector, } \mathrm{Sp}^{r}\end{array}$ & $\begin{array}{l}\text { LeBlanc et al., } \\
1992\end{array}$ \\
\hline $\mathrm{pZX} 9$ & $\begin{array}{l}\text { Streptococcal replicon with } \\
\text { xylose-inducible cassette, } \mathrm{Sp}^{r}\end{array}$ & Xie et al., 2013 \\
\hline
\end{tabular}

Sp, spectinomycin. 
identify non-expressing cells, we used a dual reporting strain. The S. mutans UA159 pGBE-PcomX::gfp/pDL278-P23::DsRedExpress2 strain was constructed using plasmid pDL278P23::DsRed-Express2, which constitutively drives production of the DsRed-Express2 fluorescent protein encoded on the E. colistreptococcal shuttle vector pDL278 (Shields et al., 2019). The plasmid was transformed into a strain of S. mutans UA159 which harbors green fluorescent protein $(g f p)$ fused to the promoter region of $\operatorname{com} X$, integrated into the chromosome at the gtfA site using plasmid pGBE (Son et al., 2018). Plasmid DNA was introduced into $S$. mutans by natural transformation using synthetic CSP peptide (sCSP, see below) synthesized by the Interdisciplinary Center for Biotechnology Research (ICBR) facility at the University of Florida with $>95 \%$ purity. The CSP was reconstituted in water to a final concentration of $2 \mathrm{mM}$ and stored in $100 \mu \mathrm{L}$ aliquots at $-20^{\circ} \mathrm{C}$.

For transformations, a final concentration of $2 \mu \mathrm{M}$ sCSP was added to growing S. mutans UA159 pGBE-PcomX::gfp cultures as they reached $\mathrm{OD}_{600} \mathrm{~nm}=0.2$ along with $500 \mathrm{ng}$ of pDL278-P23::DsRed-Express2. After $3 \mathrm{~h}$ of additional growth, transformants were plated on $\mathrm{BHI}$ agar with the appropriate antibiotics for selection. The strain was then confirmed by PCR using pDL278-specific primers (F-TCA ACT GCC TGG CAC AAT AA; R-TTT GCG CAT TCA CAG TTC TC) and then sequencing of the P23::DsRed-Express2 insert region (Eurofins Genomics). For controls we utilized a constitutively expressing $g f p$ reporter under control of the $l d h$ promoter as well as UA159 carrying an empty pDL278 plasmid (Ishkov et al., 2020).

The 18-residue form of CSP (SGSLSTFFRLFNRSFTQA) was used throughout. For imaging studies, synthetic CSP, purified to $98 \%$, was provided by NeoBioSci (Cambridge, MA, United States). The rhodamine-B labeled CSP [(Rhod_B) SGSLSTFFRLFNRSFTQA] was synthesized by Pierce Biotechnology (Rockford, IL, United States) and purified to $>90 \%$. Synthetic XIP peptide GLDWWSL, corresponding to residues 11-17 of ComS, purified to $96 \%$, was prepared by NeoBioLab (Woburn, MA, United States).

\section{Growth Conditions}

We grew S. mutans from glycerol stocks overnight in BBL Brain Heart Infusion (BHI). Strains were grown in an incubator at $37^{\circ} \mathrm{C}$ and $5 \% \mathrm{CO}_{2}$ overnight in medium that contained $1 \mathrm{mg} \mathrm{ml}{ }^{-1}$ spectinomycin. Cultures were then washed twice by centrifugation and then diluted 25 -fold in either complex medium (BHI) or defined medium (FMC) (Terleckyj et al., 1975; De Furio et al., 2017). To facilitate biofilm growth, we supplemented media with either $10 \mathrm{mM}$ sucrose (BHI) or $5 \mathrm{mM}$ sucrose and $15 \mathrm{mM}$ glucose (FMC), both with $1 \mathrm{mg} \mathrm{ml}^{-1}$ spectinomycin added (Klein et al., 2009; Xiao and Koo, 2010). We loaded $300 \mu \mathrm{L}$ of the prepared culture into a stationary 8 well slide ( $\mu$-Slide 8 well glass bottom, Ibidi United States), which was allowed to form a mature biofilm in absence of flow. The Ibidi slide consists of an array of 8 square wells (each $9.4 \times 10.7$ $\times 6.8 \mathrm{~mm}$ deep) with a glass coverslip bottom that allows the developing biofilm to be observed and imaged with an inverted microscope. Except where stated, the supernatant was exchanged with fresh growth medium without sucrose after $5 \mathrm{~h}$ of facilitated biofilm growth with sucrose. For biofilms that were tested with an inducer peptide, $1 \mu \mathrm{M}$ CSP or $1 \mu \mathrm{M}$ (rhodamine B)-CSP (for $\mathrm{BHI}$ medium) or $500 \mathrm{nM}$ XIP (for FMC medium) was added. The culture in the 8 well slide was then returned to the incubator for an additional $2 \mathrm{~h}$ before imaging.

\section{CLSM Fluorescence Imaging of Biofilms}

For confocal and multiphoton imaging, biofilms of the S. mutans wild-type UA159 and mutant strains were grown in multiwell Ibidi slides and three technical replicates were collected for each growth condition. To reduce image noise and enhance green fluorescence, slides were gently washed by removing the growth medium and replacing it with a phosphate buffer solution (Yoshida and Kuramitsu, 2002). Two-photon fluorescence images of the intact biofilms were collected using a Nikon A1RMP Multiphoton Microscope on an Eclipse Ti-E inverted fluorescent microscope frame with a Spectra-Physics Mai-Tai HP DS (Deep See) IR variable $(690-1,040 \mathrm{~nm})$ pulse laser at an excitation wavelength of $920 \mathrm{~nm}$. For conventional confocal laser scanning (CLSM) imaging, the excitation source was an LU-N4 Laser Unit set to 488 and $561 \mathrm{~nm}$ excitation wavelengths, passed through 525/50 and 595/50 $\mathrm{nm}$ filter sets, respectively. Images were acquired using a $60 \times$ water immersion objective (CFI60 Plan-Apo IR, 1.27 NA, WD $=0.16-0.18 \mathrm{~mm}$ ) and each frame was an average of four sweeps. Images of the biofilms formed stacks with $1 \mu \mathrm{m}$ vertical spacing and spanned a total depth of 35 $\mu \mathrm{m}$. For CLSM imaging of rhodamine-labeled CSP in biofilms of gfp-reporting S. mutans, a $488 \mathrm{~nm}$ excitation laser with a 525/25 green filter was used to collect green fluorescence images and the red fluorescence images were collected using a $561 \mathrm{~nm}$ excitation laser and a 595/50 nm filter.

\section{Image Analysis}

To probe for structure in the spatial distribution of individual, PcomX-active cells in the biofilm we evaluated the nearest neighbor distance (NND) distribution (Dixon, 2013). The NND distribution $f(r) d r$ is the probability that the distance $r$ from a $P \operatorname{com} X$-active cell to its nearest $P \operatorname{com} X$-active neighbor lies in the interval $r$ to $r+d r$. We found the distribution $f(r)$ using a custom Matlab code that evaluates the nearest neighbor distances $r$ within one layer of a confocal image stack. We then calculated the cumulative distribution function (CDF) of each NND,

$$
F(r)=\int_{0}^{r} d r^{\prime} f\left(r^{\prime}\right)
$$

which has the property $F(r) \rightarrow 1$ at large $r$. The experimentally determined $\mathrm{CDF}$ can be compared to $F_{0}(r)$, which is the $\mathrm{CDF}$ that would occur if an equivalent number of cells were distributed across the image plane by a homogeneous Poisson process, which is often called complete spatial randomness (CSR). If a density $n$ (cells/area) of cells is randomly (CSR) distributed over an area, the NND distribution is

$$
f_{0}(r) d r=2 n \pi \exp \left(-\pi n r^{2}\right) r d r
$$

and the $\mathrm{CDF}$ is

$$
F_{0}(r)=1-\exp \left(-\pi n r^{2}\right)
$$


This spatially random CDF must be modified slightly if, while most cells are randomly distributed, a fraction $p$ are within doublets, or pairs of cells in close proximity $\left(r<r_{c}\right)$. For this case we model the expected CDF as

$$
F_{1}(r)=p \frac{r^{2}}{r_{c}^{2}}+(1-p)\left(1-\exp \left(-\pi n r^{2}\right)\right)
$$

for $r<r_{c}$ and

$$
F_{1}(r)=p+(1-p)\left(1-\exp \left(-\pi n r^{2}\right)\right)
$$

for $r>r_{c}$. Here $r_{c}$ is the maximum separation between cells that comprise a doublet.

To assess whether the experimentally observed $F(r)$ were consistent with the random model $F_{1}(r)$, we (1) fit the CDF obtained from an image showing $N$ cells to Eqs (4.1) and (4.2) to obtain the parameters $\left(p, n, r_{c}\right)$ for that image, (2) generated a Monte Carlo simulation of $N$ cells placed randomly according to those fit parameters, and (3) evaluated the envelope of CDFs from 1,000 such simulations. This approach provides a KolmogorovSmirnov test of the agreement between the model CDF and the experimental CDF.

In order to assess the randomness of the spatial distribution of PcomX active cells on distance scales greater than the typical NND, we evaluated the Ripley's K metric for the distribution of inter-cellular distances (Ripley, 1976; Dixon, 2013). Ripley's $\mathrm{K}$ is widely used in spatial ecology as a test for clustering or dispersion of objects that are distributed in two-dimensions. We used a custom Matlab code to evaluate Ripley's $\mathrm{K}$ for the distances between Pcom $X$-active cells within an image layer, using the buffer zone method to reduce edge artifacts (Ripley, 1976; Haase, 1995).

\section{RESULTS}

\section{CSP Elicits Heterogeneous PcomX Activity in S. mutans Biofilms in Complex Medium}

CSP elicits a bimodal (subpopulation-only) response from S. mutans comX in complex growth media such as BHI, whether cells are grown under uniform, microfluidic flow conditions (Son et al., 2012) or in a biofilm (Aspiras et al., 2004). We first confirmed that our confocal imaging could probe this bimodal response at the individual cell level.

Figure 1 shows two-color CLSM fluorescence images of biofilms of the dual reporting PcomX-gfp/P23-rfp strain growing in BHI medium. As described in section "Materials and Methods," biofilms were grown for $5 \mathrm{~h}$ in BHI and then incubated for $2 \mathrm{~h}$ in fresh medium that contained $1 \mu \mathrm{M}$ synthetic CSP (Figures 1A,B), or no added CSP (Figures 1C,D), prior to a buffer wash and imaging. The constitutive red fluorescence of individual cells was strong whether CSP was provided or not, revealing the clustered morphology of the biofilms. Green fluorescence indicating $\operatorname{com} X$ expression was detected only in biofilms that were provided synthetic CSP: Figures 1A,B show
PcomX-active cells as a small, mostly dispersed subpopulation of green cells. This is qualitatively consistent with the bimodal $\operatorname{com} X$ response to CSP observed in planktonic cultures, although we estimate the $\operatorname{com} X$-active subpopulation in the biofilm at only $3-4 \%$, much fewer than the $30-40 \%$ of cells that respond to CSP in planktonic conditions (Son et al., 2012; Fontaine et al., 2015).

Supplementary Figure S1 shows the two-color CLSM fluorescence images of biofilms of the non-reporting UA159 strain growing in the same conditions as PcomX-gfp/P23-rfp in Figure 1. As expected, Supplementary Figure S1 shows the absence of any fluorescence on the brightness scale of Figure 1, indicating that the red and green fluorescence in Figure $\mathbf{1}$ is due to the fluorescent reporters in the PcomX-gfp/P23-rfp strain rather than any background fluorescence.

Although Figures 1B,D show that the density of both red fluorescence and PcomX-active cells was greatest on the bottom (glass contact) layer of the biofilms, individual $\operatorname{com} X$-expressing cells are visible throughout the depth of the biofilm and appear mostly well-separated. Figure 1E shows that roughly 10-20\% of comX-active cells are paired into fluorescent doublets, where each doublet consists of two closely adjacent cells that are axially coaligned to form a bow-tie shape.

\section{CSP Diffuses Rapidly Through the Biofilm}

We tested the permeability of an S. mutans biofilm to diffusion of CSP. We grew a constitutively reporting Pldh-gfp strain in BHI medium with $10 \mathrm{mM}$ sucrose in a multiwell slide. After $5 \mathrm{~h}$, the medium was exchanged for fresh BHI without sucrose and incubated for an additional $4 \mathrm{~h}$. One micrometer synthetic CSP, which was synthesized with an $N$-terminal label of rhodamine $B$ (red) fluorophore, was then added to the different wells at different times. In this way the biofilms were supplied dye-labeled peptide for different time durations, ranging from $7 \mathrm{~min}$ to $4 \mathrm{~h}$, before the medium in all wells was exchanged for a phosphate buffer solution and the biofilms were imaged in CLSM.

The red fluorescence of the rhodamine $B$ was seen to quickly concentrate in small pockets of elliptical shape, with length up to $2-3 \mu \mathrm{m}$. The pockets are visible throughout the depth of the biofilm, even in the earliest images after 7 min of diffusion. Figures 2A,B show these pockets at the bottom (substrate) layer and $5 \mu \mathrm{m}$ above the bottom, respectively, of each biofilm. This pattern of fluorescence was unchanged after $4 \mathrm{~h}$ of diffusion. Interestingly we found no such fluorescent pockets when soluble rhodamine B (no peptide) was added to the biofilm (Supplementary Figure S2), indicating that the pockets of red fluorescence were not due to rhodamine B binding a specific target such as eDNA (Islam et al., 2013). Analysis of the CLSM images (Supplementary Figures S3, S4) shows that the red fluorescent pockets did not physically overlap with green fluorescence and therefore were not due to staining of live cells. Rather, imaging of planktonic cells incubated with rhodamine-B-CSP (Supplementary Figure S5) indicated that the CSP associates with certain non-cellular material. Nevertheless, the rapid permeation of the rhodamine-CSP into the biofilm, with nearly immediate formation of a stable red fluorescence 

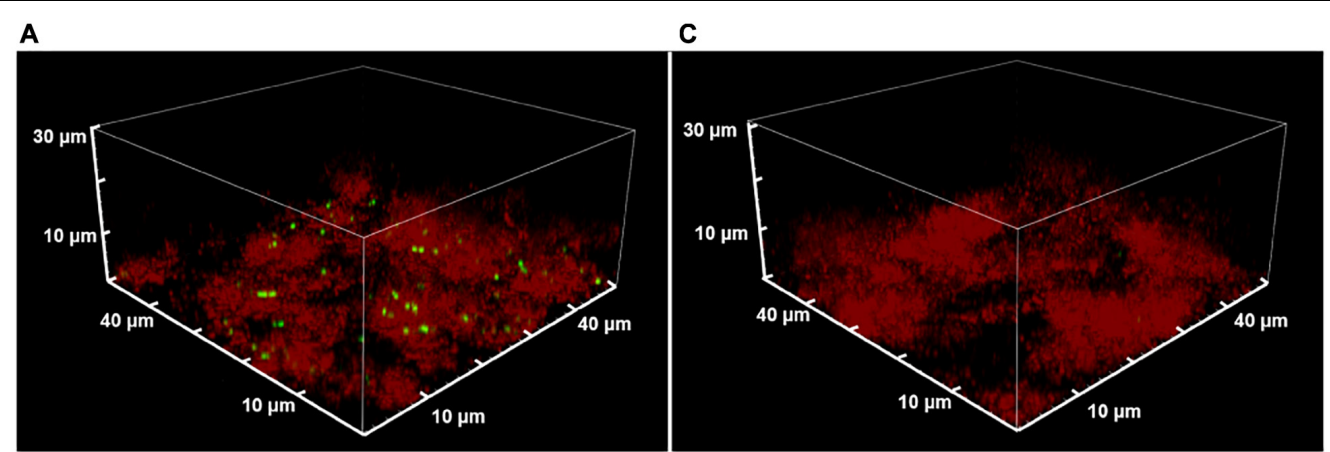

B

D

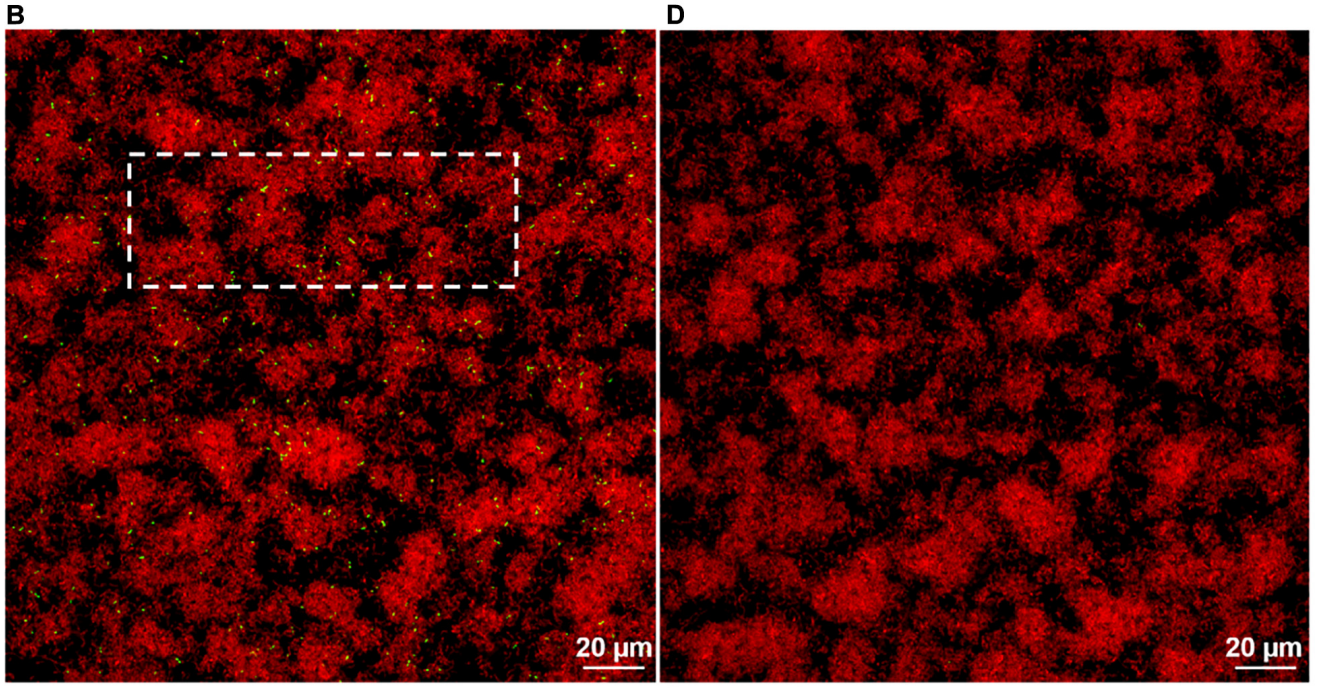

E

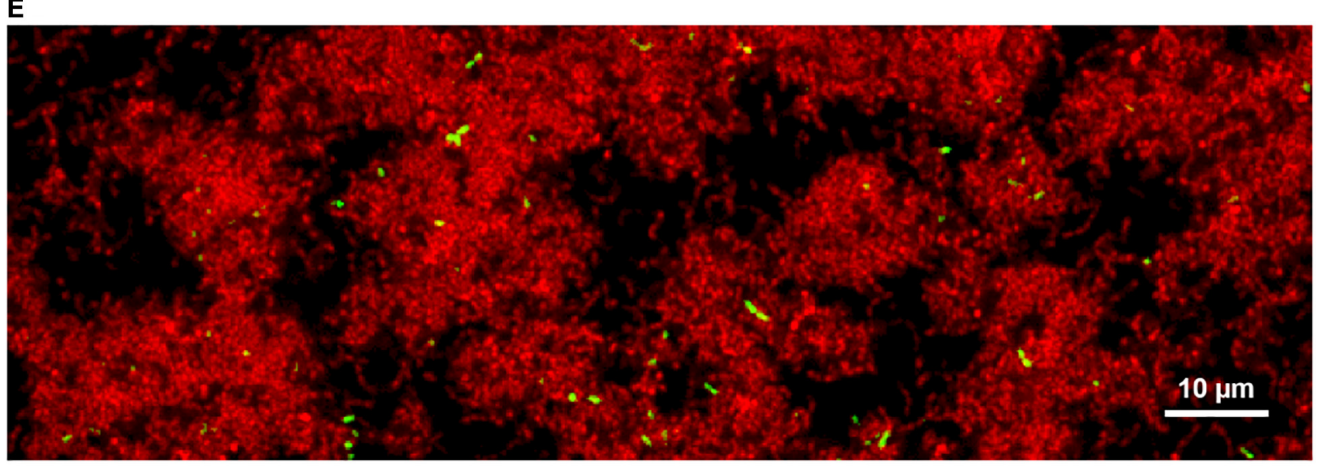

FIGURE 1 | A 3D confocal image stack (A) and the substrate layer image (B) of a biofilm of the dual reporting (PcomX-gfp/P23-rfp) strain grown for $5 \mathrm{~h}$ before an additional $2 \mathrm{~h}$ incubation in fresh BHI with $1 \mu \mathrm{M}$ synthetic CSP. (C,D) The same strain without addition of CSP. (E) An expanded view of the dotted region in (B)

Three technical replicates were collected of the data shown for each condition and the experiment was performed three times.

pattern, verified that CSP is mobile through the depth of the BHI-grown biofilm.

\section{ComX-Expressing Cells Within a 2D Slice of Biofilm Tend Toward a Random Distribution}

We used the distribution of near-neighbor distances (NNDs) as a test of spatial correlations between PcomX-active cells, which could indicate regions where competence behavior is localized (Dazzo et al., 2013), such as through restricted diffusion of the XIP intercellular signal (Kaspar et al., 2017). Figures 3A,C,E show the distribution $f(r)$ of the NND values (distances between nearest neighbors in see section "Materials and Methods") for PcomX-active cells in 2D cross-sections such as that of Figure 1B. The image in Figure 1B contains $N=492$ green cells; the red curve in Figure $3 \mathbf{A}$ shows the NND distribution $f_{0}(r)$ that would be expected if 492 cells were distributed across the image plane 

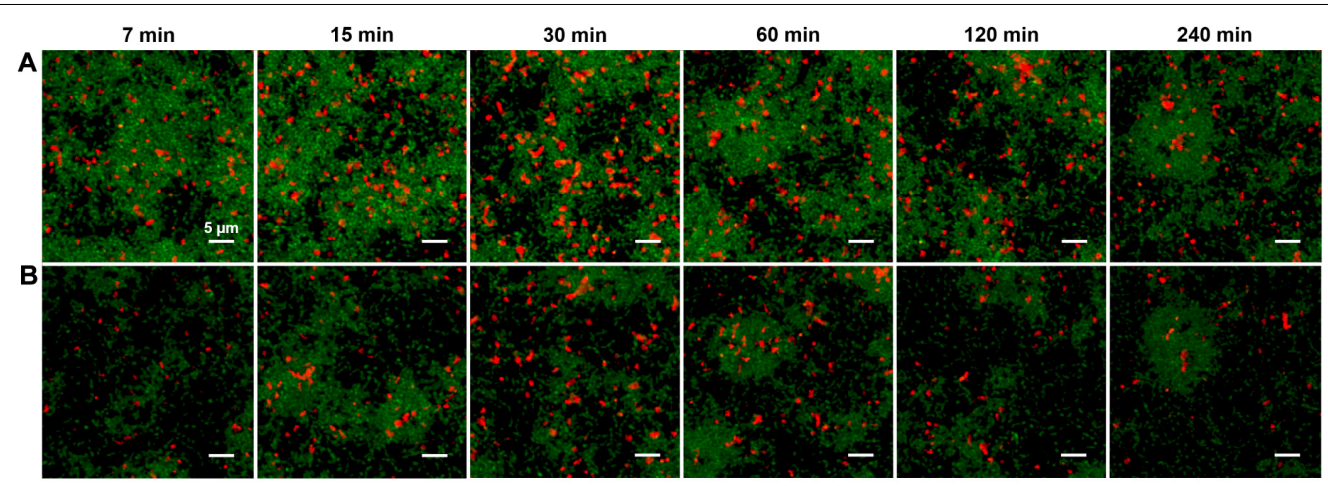

FIGURE 2 | (A) CLSM images of the substrate layer of a constitutive gfp reporting S. mutans strain grown for $5 \mathrm{~h}$ in BHI and then incubated (for the time intervals indicated) with $1 \mu \mathrm{M}$ rhodamine B labeled synthetic CSP. The green channel corresponds to the constitutive gfp reporter and the red channel shows rhodamine B fluorescence. The total intensity of the red fluorescence in the image reached its full value within 30 min of diffusion. (B) CLSM Images at the same $x y$ locations as in (A) but $5 \mu \mathrm{m}$ above the substrate. Three technical replicates were collected of the data shown for each condition and the experiment was performed three times.
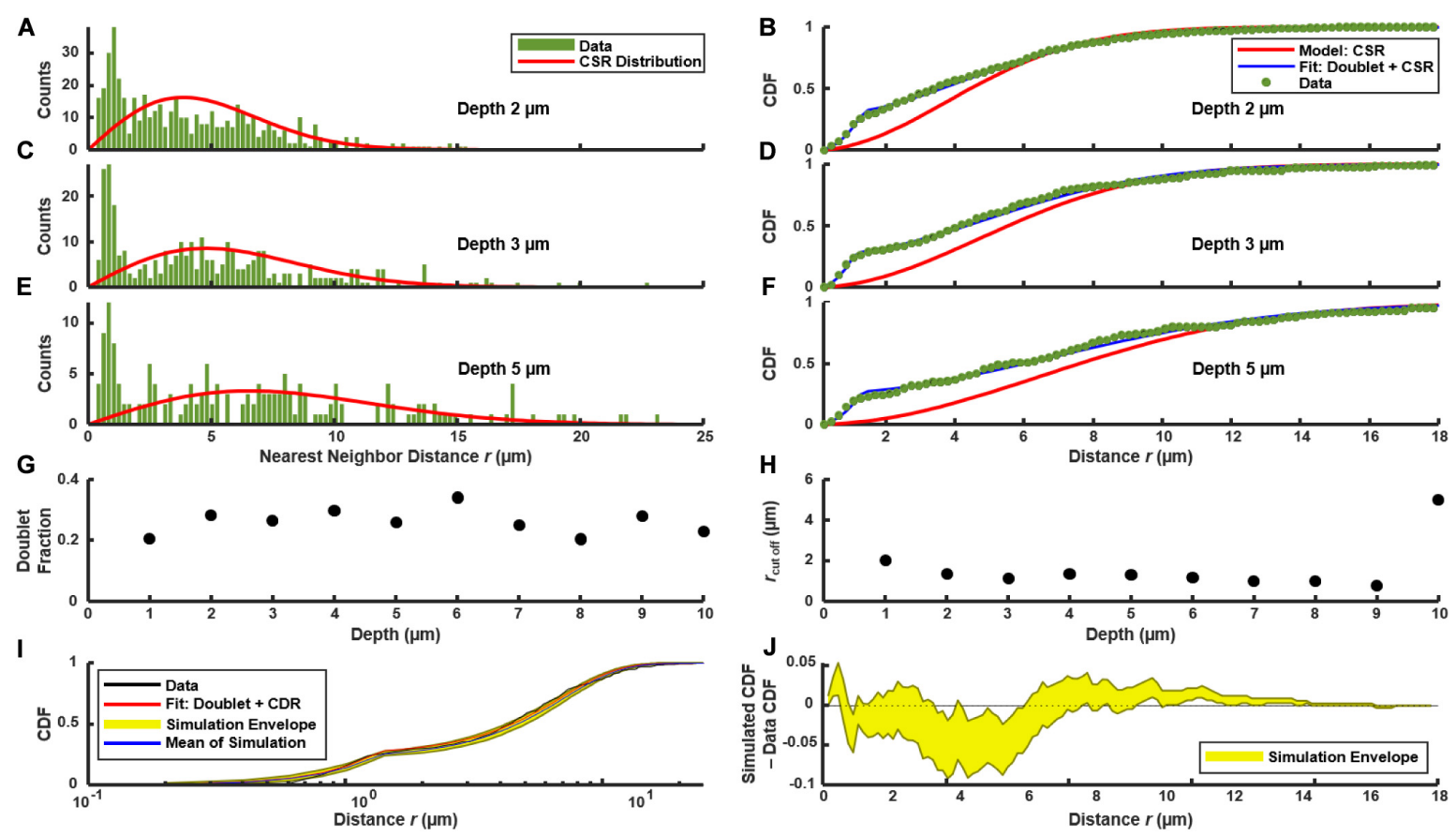

FIGURE 3 | Distribution of nearest neighbor distances between PcomX-expressing cells in the biofilm of Figures 1A,B following addition of CSP. (A,C,E) NND histogram $f(r)$ (green) of data, and theoretical $f_{0}(r)$ (red) which corresponds to complete spatial randomness (CSR). (A,C,E) $f(r)$ and $f_{0}(r)$ at depths of 2,3 , and $5 \mu \mathrm{m}$, respectively, within the biofilm. (B,D,F) Cumulative distribution function $F(r)$ of data (green), and theoretical $F_{0}(r)\left(\right.$ red) which corresponds to CSR. The theoretical $F_{1}(r)$ (blue) for the doublet+random model is also shown in (B,D,F) and was obtained from a fit of Eqs (4.1) and (4.2) to the experimental $F(r)$. (G,H) Doublet fraction $p$ and cutoff $r_{c}$ obtained from fitting experimental CDF to Eqs (4.1) and (4.2) at different depths in the biofilm, from 1 to $10 \mu \mathrm{m}$ above the substrate layer.

(I) Kolmogorov-Smirnov test by Monte Carlo simulation of the doublet+random model: 1,000 simulations were performed of cells randomly distributed in two dimensions with the same total number and density as observed in (C), using the fit parameters of $F_{1}(r)$ found in (D). (J) The difference between the experimental $F(r)$ and the CDF obtained from the Monte Carlo simulations in (I). The yellow envelope in (I,J) represents the 90th and 10th percentiles from 1,000 simulations.

with complete spatial randomness (CSR in section "Materials and Methods"). Figure 3B shows $F(r)$, the CDF of the green fluorescent cells, with $F_{0}(r)$ (red curve), which is the NND CDF for a random spatial distribution of 492 cells. Figures $3 \mathrm{C}-\mathrm{F}$ repeat the NND and CDF analyses at layers further from the substrate. In all cases the true NND distribution and CDF show an excess (relative to the CSR model) at NNDs near 1-2 $\mu \mathrm{m}$. This deviation indicates that $\operatorname{com} X$-active cells have some tendency to collocate at this separation.

The confocal images in Figures 1A,B suggest that the anomaly at short distances is a consequence of the cell doublets-pairs of closely adjacent green fluorescent cells. As these doublets have the appearance of sister cells that are not fully separated, we considered that they are likely not due to competence-favoring 
microenvironments. Rather they correspond to partially attached daughter cells that have inherited the same state of the PcomX bimodal switch (Hagen and Son, 2017) from their parent cell. Supplementary Figure S6 shows that very similar fluorescent doublets are present after a well-stirred, planktonic culture is incubated with CSP. Therefore we compared our biofilm NND histograms and CDF to a slightly modified spatially random model (see section "Materials and Methods"). The model considers a density $n$ of green fluorescent cells that are distributed randomly and homogeneously across the image, where a fraction $p$ of these cells have by chance a sister cell within a short distance $r<r_{c} . F_{1}(r)$ is the CDF for this model. It is given by Eqs (4.1) and (4.2), where the cutoff distance $r_{c}$ defines the maximum separation of cells within a doublet.

Figures 3B,D,F compare $F(r)$ (the experimental CDF) with least-squares fits to the doublet model $F_{1}(r)$. The fit parameters $r_{c}$ $\simeq 1.5-2 \mu \mathrm{m}$ and $p \simeq 0.2-0.3$ are mostly consistent throughout the depth of the biofilm (Figures 3G,H). To assess the significance of any disagreement between the experimental CDF and the model we performed a Kolmogorov-Smirnov test, based on a Monte Carlo approach (see section "Materials and Methods"). Briefly, we simulated the random (with doublets) distribution of an equivalent number of points in a two-dimensional plane, using parameters $n, r_{c}$ and $p$ obtained from fitting the experimental data. We then evaluated the CDFs for these simulated distributions and compared them to the experimental distribution. As shown by Figures 3I,J, the experimental CDF is found to lie within the $10-90 \%$ range of the 1,000 simulated CDFs. Overall the doublet model provides good agreement with the experimental NND distributions. (Small deviations between the data and Eqs (4.1) and (4.2) at distances greater than $\sim 10$ $\mu \mathrm{m}$ likely result from finite image size). The data are therefore consistent with the null hypothesis that, aside from a small number of attached sister cells, the spatial distribution of $\operatorname{com} X$ expressing cells in the images lacks structure on length scales less than $10-20 \mu \mathrm{m}$.

To test for spatial correlations on longer length scales, extending beyond nearest PcomX-active neighbors, we applied a test based on Ripley's K (Ripley, 1976; Haase, 1995). We calculated, for each PcomX-active cell in an image, the number of other active cells that lie within a radius $r . K(r)$ is the average (over all cells) of this number, divided by the mean area density of active cells. By comparing $K(r)$ to the value expected for CSR (Kiskowski et al., 2009), spatial correlations on long length scales can be detected.

In order to remove the quadratic behavior of $K(r)$ that is characteristic of CSR, the function $H(r)$ is often used (Haase, 1995; Hart et al., 2019):

$$
H(r)=\sqrt{\frac{K(r)}{\pi}}-r
$$

$H(r)=0$ indicates complete spatial randomness, while $H(r)>0$ indicates clustering on spatial scales up to $r$.

Figure 4A shows $H(r)$ calculated for the 492 PcomXexpressing cells in the 2D layer of Figure 1B. The shaded region is the 90th and 10th percentile envelope from 1,000 trials of
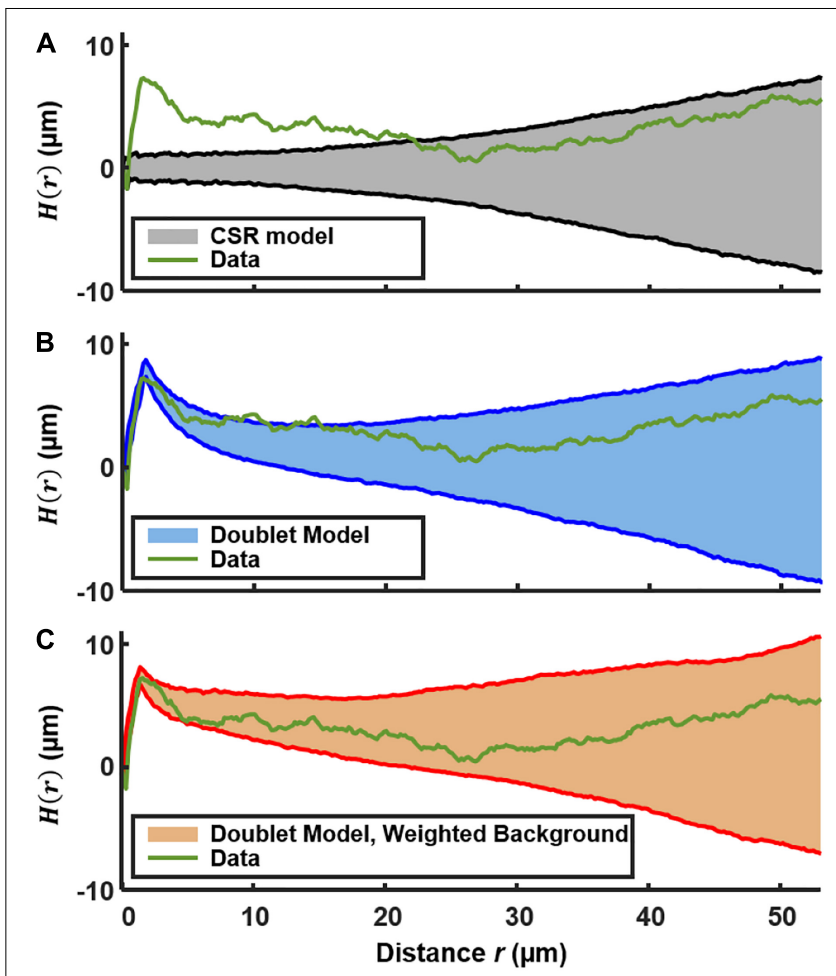

FIGURE 4 | Ripley's K analysis showing the $H(r)$ (green curve) for the comX-active cells in the biofilm layer of Figures 1A,B. (A) Comparison of $H(r)$ to the envelope of 1,000 simulations (shaded region) of $H(r)$ for 492 cells randomly distributed over the same area. The shading indicates the 10 th and 90th percentiles of the simulated $H(r)$. (B) Comparison of $H(r)$ to the envelope of simulations of 492 cells distributed by the doublet+random model.

(C) Comparison of $H(r)$ to the envelope of simulations of 492 cells distributed by the doublet+random model, where non-doublet cells are placed at random locations that are weighted according to the red fluorescent (live cell) background of Figure 1B.

simulated $H(r)$, each obtained by evaluating $H(r)$ for 492 points distributed randomly (CSR) over equivalent area. The shortrange (sister cell) clustering that was detected in the NND analysis causes the experimental $H(r)$ to exceed the envelope of the CSR simulations at distances near $2 \mu \mathrm{m}$, and $H(r)$ remains outside the CSR envelope up to distances near $20 \mu \mathrm{m}$. Figure 4B shows that including the presence of active sister-cells in the simulation of randomly distributed cells improves the agreement between the experimental and simulated $H(r)$. However, some possible deviation of $H(r)$ from the doublet+random model is apparent at $r=10-15 \mu \mathrm{m}$.

We do anticipate some deviation of $H(r)$ from CSR behavior on this length scale because the density of the EPS matrix and microcolony biomass itself varies on this scale (Xiao and Koo, 2010). The locations of green fluorescent cells should generally correlate with the distinctly non-uniform pattern of constitutive red fluorescence in Figure 1. Therefore we calculated $H(r)$ for simulations of a nearly random spatial model in which (1) a density $n$ of green fluorescent cells is distributed across the image, at locations randomly sampled according to a distribution that is weighted by the red fluorescent background in Figure 1B, and 
(2) a fraction $p$ of the green fluorescent cells are part of a sistercell doublet. This model places green fluorescent cells (including doublets) at random locations, but with a spatial weighting that matches the heterogeneous density of live cells in the biofilm.

Figure 4C compares the experimental $H(r)$ with that obtained by simulations of this sister-cell + background-weighted model, generated using the $r_{c}, n$, and $p$ parameters extracted above. The experimental $H(r)$ falls within the $10-90 \%$ envelope of 1,000 simulations of the model. Consequently the Ripley's analysis supports the null hypothesis that the distribution of $\operatorname{com} X$ expressing cells is generally random and homogeneous, with the exception of sister-cell associations on a very short scale and the variations in the biofilm density on larger length scales. The data give no indication of clustering on scales of roughly 5-20 $\mu \mathrm{m}$, which might signify microenvironments in which $\operatorname{com} X$ activity is correlated through local signaling.

\section{Correlation Between PcomX Activity and CSP Accumulation}

Although Figure 2 confirms that CSP permeates the depth of the biofilm, we investigated whether heterogeneity in CSP concentrations on short length scales could affect the spatial distribution of PcomX activity. We used Figure 2 to test whether $\operatorname{com} X$ active cells were more likely to lie in proximity to the sites of accumulated CSP revealed by the rhodamine-B label.

Figure $\mathbf{5 A}$ shows a confocal image of the substrate layer of a biofilm of the PcomX-gfp strain, grown in BHI with $10 \mathrm{mM}$ sucrose for $5 \mathrm{~h}$. Spent medium was exchanged for fresh $\mathrm{BHI}$ (no added sucrose) containing $1 \mu \mathrm{M}$ rhodamine-B labeled CSP, and the biofilm was then incubated for $2 \mathrm{~h}$ before washing and imaging. Figure 5B shows the histogram of distances from each PcomX-active cell to the nearest red fluorescent CSP site. Figure 5B also compares that distance histogram to that of a fully randomized distribution, wherein the same number of PcomX-active cells are placed at completely random locations with respect to the same set of red fluorescence sites. To make that comparison we performed 1,000 simulation trials in which the PcomX-active cells in the image were randomly repositioned within the image field, and the histogram of distances to the nearest red site recalculated; the gray envelope in the figure defines the 90th and 10th percentiles from these simulations. The histogram evaluated from the true locations of the $\operatorname{com} X$ active cells falls well within this random envelope, indicating the comX-expressing cells are not closer, on average, to the CSP-rich sites than would be expected from chance.

\section{Responsivity to XIP Peptide in Defined Medium Declines in Aged Biofilm}

It was previously reported that, when $S$. mutans biofilms were grown in chemically defined medium for periods up to $\sim 20 \mathrm{~h}$, the ability of XIP to induce the (unimodal) $\operatorname{com} X$ response began to decline (Shields and Burne, 2016). We tested whether this response to XIP remains population-wide (unimodal), as it does for planktonic cells growing in chemically defined medium (Son et al., 2012), or whether the $\operatorname{com} X$ response is limited to a subpopulation (Shields and Burne, 2016). We grew biofilms of the PcomX-gfp strain and a xylose-inducible control, P $x y l-g f p$, in the defined medium FMC with $5 \mathrm{mM}$ sucrose and $15 \mathrm{mM}$ glucose for 5,10 , and $20 \mathrm{~h}$. The medium was then exchanged with fresh FMC containing $500 \mathrm{nM}$ synthetic XIP and $15 \mathrm{mM}$ glucose for the PcomX-gfp biofilms, or $5 \mathrm{mM}$ maltose and $6.66 \mathrm{mM}$ xylose for the Pxyl-gfp biofilms. Biofilms were then incubated for $3 \mathrm{~h}$ and, immediately prior to two-photon imaging, all media were exchanged with phosphate buffer.

Figures 6A-F shows two-photon images of the green fluorescence of biofilms that were grown for 5, 10, or $20 \mathrm{~h}$ prior to induction by XIP or xylose. Rather than segmenting individual cells in the confocal image stacks, we characterized the variability in individual cell brightness by coarse-graining the images into cell-sized volumes. We aggregated the data into voxels of $4 \times$ $4 \times 1$ pixels $\left(0.83 \times 0.83 \times 1 \mu \mathrm{m}^{3}=0.69 \mu \mathrm{m}^{3}\right)$ and generated histograms of the brightness of these binned voxels.

Both the PcomX-gfp (Figure 6A) and Pxyl-gfp (Figure 6D) biofilms show robust fluorescence at $5 \mathrm{~h}$, significantly brighter than the uninduced controls (Supplementary Figure S7). The fluorescence of the PcomX-gfp is brighter but more heterogeneous than that of the Pxyl-gfp, although both histograms show unimodal (population wide) fluorescence. The fluorescence of the PcomX-gfp biofilm declines as the biofilm ages, Figures 6G-I, while the Pxyl-gfp biofilm shows a more constant fluorescence histogram over time, Figures 6J-L.

The XIP-induced images are qualitatively unlike the CSPinduced image of Figure 1B, in which isolated, brightly fluorescent cells are separated by substantial regions lacking $\operatorname{com} X$ activity. The P $\operatorname{com} X$ response to XIP remains populationwide (unimodal), leading to histograms of GFP fluorescence in Figures 6G-I that are broad but nevertheless single-peaked. These data indicate that even in the aging biofilm, the mobility of XIP is sufficient, and microenvironments are sufficiently accommodating to competence gene expression, to activate comX throughout the biofilm, giving an overall response that is similar to that observed in well-mixed, planktonic cultures.

We note that the PcomX response to XIP can appear bimodal if the histograms are constructed using a logarithmic fluorescence scale. Supplementary Figure S8 shows that with logarithmic binning, the fluorescence histograms for both the PcomX and the $\mathrm{P} x y l$ reporter strains acquire a two-humped character, similar to Shields and Burne (2016). However, this shape is due to logarithmic binning of a near-exponential distribution; it is not an indicator of bimodal gene expression.

\section{DISCUSSION}

The response of $S$. mutans $\operatorname{com} X$ to the exogenous signals XIP and CSP is complex, even when cells are grown in precisely defined, microfluidic conditions (Hagen and Son, 2017). Here we have used confocal microscopy to characterize how heterogeneity in competence gene expression, and particularly the bimodal response of $\operatorname{comX}$ to the CSP signal, is affected by the biofilm environment.

Confocal microscopy has been invaluable for probing the structure of the EPS matrix and the organization of microcolonies 

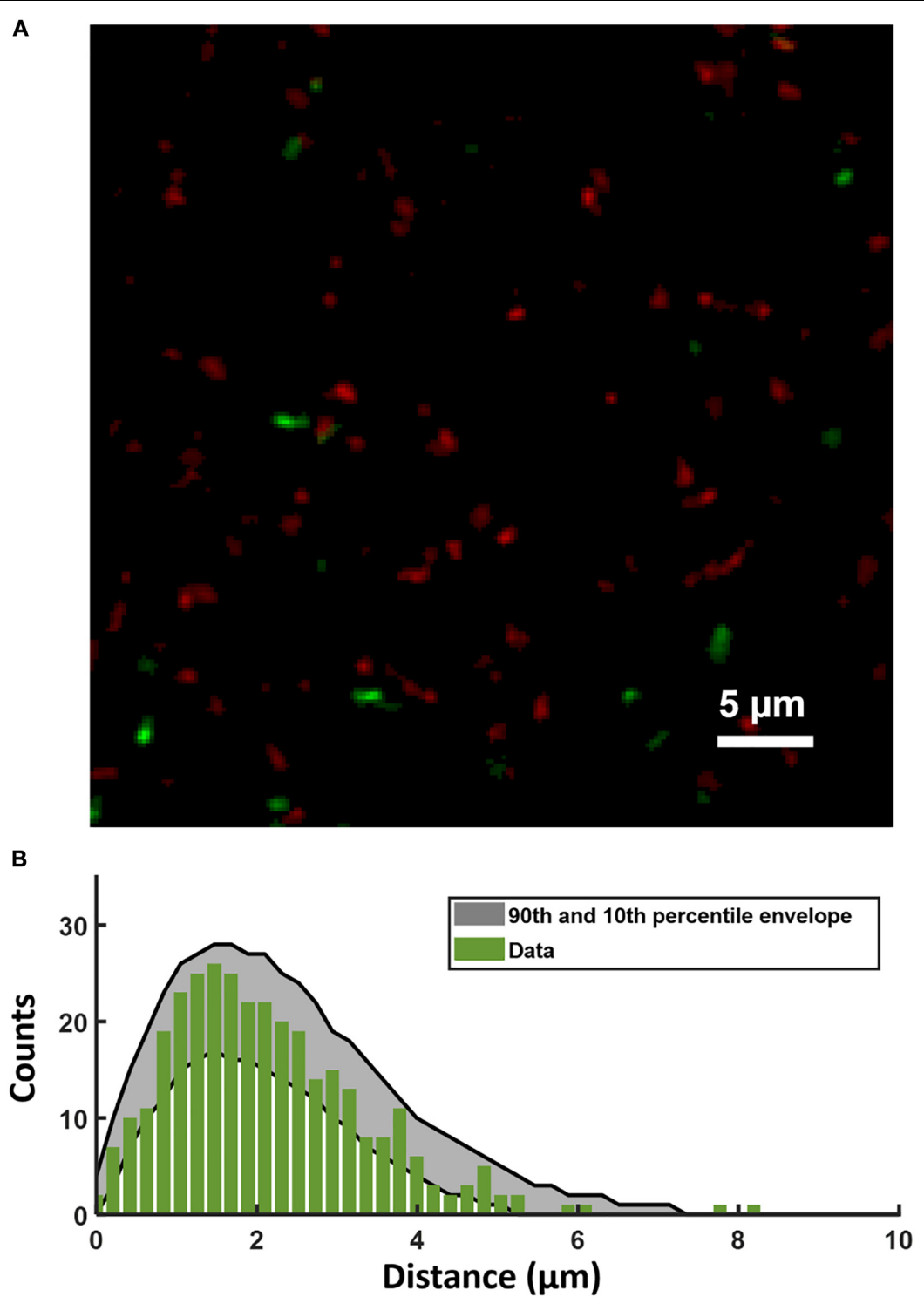

FIGURE 5 | (A) Portion of the two-color image of the substrate layer of a PcomX-gfp (plasmid) biofilm grown for $5 \mathrm{~h}$ in BHI and incubated with $1 \mu \mathrm{M}$ rhodamine-B (red) labeled CSP for $2 \mathrm{~h}$. (B) Histogram (green bars) of distances from PcomX-active (green fluorescent) cells to the nearest rhodamine CSP-rich (red fluorescent) site; The gray envelope represents the 90 th and 10 th percentiles from 1,000 simulations of the green-to-red nearest distance histogram after the comX-expressing cells have been randomly relocated throughout the image. Three technical replicates were collected of the data shown.

in S. mutans biofilms (Xiao and Koo, 2010), and for exploring spatial positioning or spatial ecology of $S$. mutans within mixed species biofilms (Nakanishi et al., 2018; Kim et al., 2020). Imaging has shown that cell vitality, respiratory activity and EPS production are distributed non-uniformly in S. mutans biofilms (Decker et al., 2014). Several studies have explored competence behavior in biofilms through the imaging of fluorescent genereporter strains (Aspiras et al., 2004; Shields and Burne, 2016; Kaspar et al., 2017). Aspiras et al. (2004) found that green fluorescence in a biofilm of a PcomX-gfp reporting strain was sparsely expressed following addition of exogenous CSP, with fewer than $1 \%$ of cells responding to the stimulus. ComCDE and ComRS have been described as quorum sensing systems operating through CSP and XIP signaling, respectively, and the sparse response of $\operatorname{com} X$ could imply that restricted diffusion or other local effects in the biofilm modulate expression of the competence genes (Aspiras et al., 2004; Kaspar et al., 2017). The increase of EPS in response to elevated sucrose, for example, could impact the diffusion of XIP within the S. mutans biofilm (Klein et al., 2009; Xiao and Koo, 2010; Kaspar et al., 2017). Aspiras et al. (2004) suggested that comX expression may be localized to small clusters of cells, occupying discrete microniches that provide favorable conditions of cell density, nutrient and other factors. Modeling studies have also anticipated spatial correlations or clustering in quorum activity inside bacterial biofilms (Hense et al., 2007; Kindler et al., 2019). 

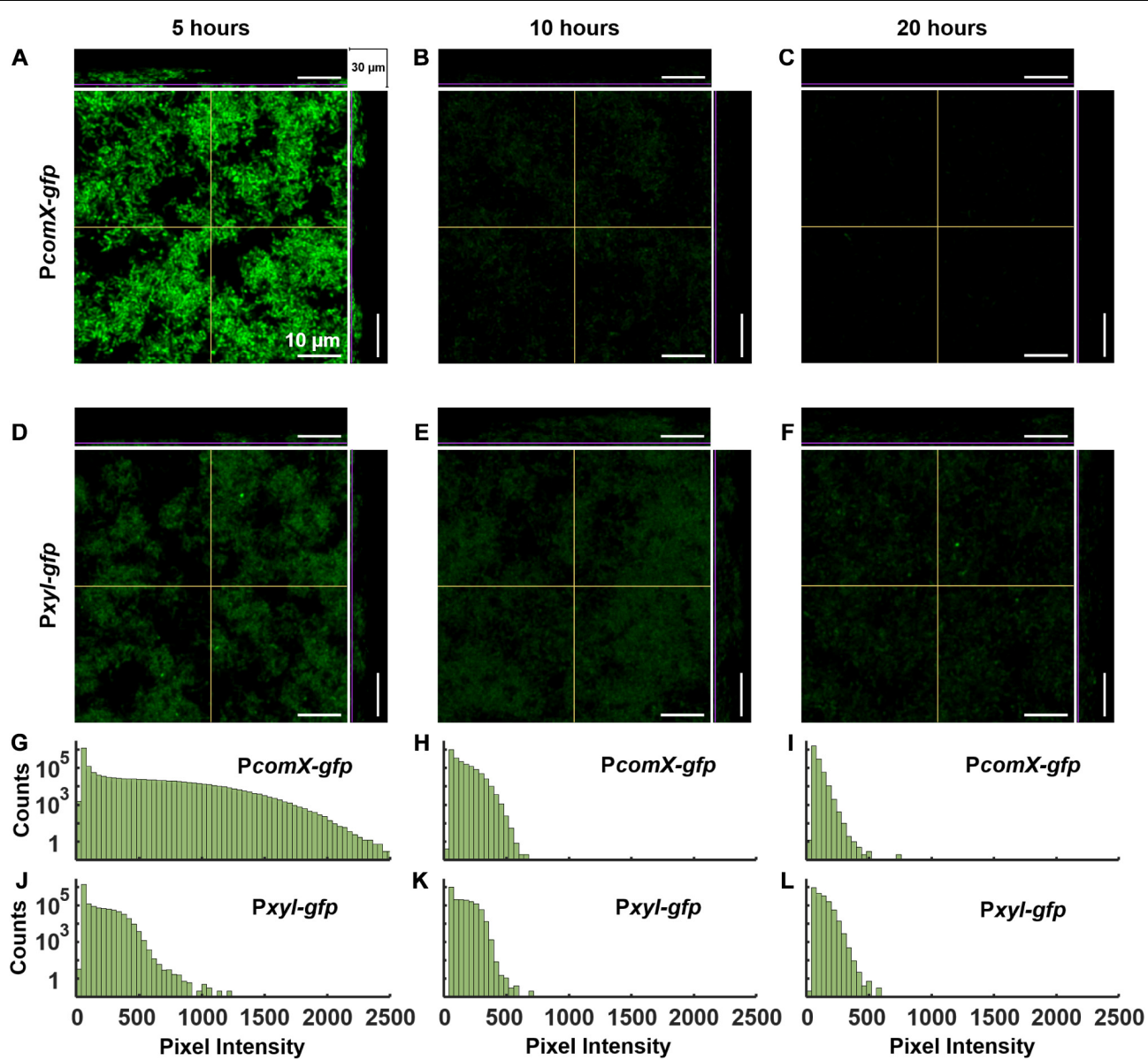

FIGURE 6 | Activation of PcomX-gfp (plasmid) grown in FMC media for (A) 5, (B) 10 and (C) $20 \mathrm{~h}$ before being incubated with $500 \mathrm{~nm}$ XIP for an additional $3 \mathrm{~h}$. A Pxyl-gfp strain induced with xylose (at the same time as XIP was added for PcomX-gfp) grown in FMC media for (D) 5, (E) 10 , and (F) $20 \mathrm{~h}$ under the same conditions as (A-C). (G-L) Brightness intensity histograms of 16 pixels at a time throughout the depth of the biofilms in (A-F), respectively. All images were obtained by two-photon microscopy with $920 \mathrm{~nm}$ excitation wavelength and a 525/25 green filter. The middle panel in each multiphoton image shows the 2D $x-y$ plane. The depth (z) of this plane within the biofilm is represented by the purple lines on the adjacent top and side panels which show the $x-z$ and $y-z$ planes, respectively. The $x$ and $y$ regions of the adjacent planes are represented by the yellow lines on the 2D, $x-y$ plane. The total stack depth is $30 \mu \mathrm{m}$. The brightness scale runs from 0 to 2,500 fluorescence units in (A-C) and 0-1,500 in (D-F). Three technical replicates were collected of the data shown for each condition. Seventeen separate biofilms were grown and analyzed altogether.

Diffusion in biofilms is affected by molecular charge and mass, interactions with biofilm constituents, and the porosity of the biofilm (Stewart, 2003; Marcotte et al., 2004; Zhang et al., 2011). High molecular weight solutes such as dextrans and PEG were found to diffuse through $S$. mutans biofilms at half their free (aqueous solution) rate (Zhang et al., 2011), with lower mobility at the base of the biofilm (Marcotte et al., 2004). Uncharged fluorophores like rhodamine B were found to diffuse more slowly than charged fluorophores. However, reductions in diffusion coefficients were generally not large. Although our data suggest that rhodamine B - CSP interacts with a constituent of the matrix, the diffusion coefficient $D=1.8 \times 10^{-6} \mathrm{~cm}^{2} / \mathrm{s}$ of rhodamine B in S. mutans biofilms was measured at $40 \%$ of its value in water, indicating that the biofilm will not dramatically slow the kinetics of equilibration (Zhang et al., 2011). In biofilms of S. oralis and S. gordonii, even large (40-70 kDa) dextrans penetrated $100 \mu \mathrm{m}$ cell clusters within roughly 1-2 min (Takenaka et al., 2009).
The quorum sensing signals that modulate $S$. mutans competence are understood to be CSP and XIP, and so even in the high population-density environment of the biofilm the competence pathway is expected to remain sensitive to these signals. However, the above studies imply that the biofilm matrix has a modest effect on the diffusion of the XIP and CSP peptides. Our data are consistent with that expectation. Although the rhodamine B labeled CSP appeared to concentrate in discrete locations, these locations formed rapidly throughout the depth of the biofilm. In the resulting equilibrium, PcomXactive cells were not more likely to be near the CSP-rich locations than elsewhere in the biofilm, indicating that their $\operatorname{com} X$ activity was not triggered by localized high concentrations of CSP. Exogenously added XIP also appeared to diffuse readily through the biofilms.

Consequently, the spatial distribution of $\operatorname{com} X$ activity suggests that restricted diffusion does not lead to the formation 
of clusters or microniches of competence gene expression. The spatial distribution of active cells provides insight into whether other favorable conditions such as $\mathrm{pH}$, nutrients, oxidative stress, carbohydrate availability etc., lead to clustering of competence behavior. Dazzo (2012) and Dazzo et al. (2013) demonstrated that statistical methods such as Ripley's $K$ and the NND distribution provide a quantitative and statistically rigorous alternative to methods based on sender/receiver fluorescent reporter constructs (Gantner et al., 2006; Kaspar et al., 2017), and that these statistical tools can be far more sensitive than simple visual inspection of biofilm images. They can identify positive or negative spatial correlations, indicative of cell-to-cell communication. The NND can readily distinguish aggregation from CSR (Dazzo, 2012), while Ripley's $K$ revealed the presence of two types of local interactions in a biofilm, with length scales of 6-8 and $36 \mu \mathrm{m}$, respectively (Dazzo et al., 2013).

The NND for PcomX-activity (in response to CSP) was consistent with a simple model in which roughly $80 \%$ of $\operatorname{comX}$ expressing cells are distributed with spatial randomness-more precisely a homogeneous Poisson process. The remaining 20\% of cells are closely proximal to and physically aligned with cells in the first group, indicative of sister cell doublets that have inherited the same state $(O N$ or $O F F)$ of the $\operatorname{com} X$ bimodal switch from their parent cell. The excellent agreement between the observed NND distribution and the theoretical distribution for this model supports the null hypothesis that $\operatorname{com} X$ expression is not significantly clustered into niches or islands. Alternatively, if such niches exist, they are small enough that they comprise at most a solitary cell (or doublet). Although the Ripley's $K$ analysis indicates some deviations from pure spatial randomness, these effects appear attributable to the correlations between sister-cells and the microcolony morphology of the biofilm itself.

Nevertheless it is interesting that the fraction of cells activating in the biofilm - not more than a few percent-is much smaller than under planktonic conditions. If in the biofilm CSP activated $\operatorname{com} X$ at the same $30 \%$ average rate that is typical of planktonic conditions, the average distance between active cells in the biofilm would have been much smaller in our study. We would then have been able to detect spatial variations in that density, and possibly identify microenvironments in which that activation rate differed from the average. The fact that activation was closer to $1 \%$, which is too sparse to allow any such analysis, suggests that conditions throughout the biofilm are generally unfavorable. Local conditions such as $\mathrm{pH}$ could bias the $\operatorname{com} X$ bimodal switch to the extent that very few cells are able to accumulate enough intracellular ComS to activate the transition from $\operatorname{comX} O F F$ to $O N$. In this case the competence microniches consist of rare locations where one cell (or a doublet) is able to activate. To test this possibility it may be useful in future studies to apply spatially resolved probes of key environmental inputs such as $\mathrm{pH}$ and nutrient condition and correlate these with $\operatorname{com} X$ activity. In addition it is possible that other elements of the competence regulatory pathway are impacted by the biofilm environment. It would be interesting to test, for example, whether activity of the ComDE two component system, which senses the CSP signal, is spatially homogeneous in the biofilm.
Similarly, the expression of $\operatorname{com} R$, which controls the bimodal switch (in response to CSP stimulation) is an important control on the percentage of cells responding to CSP (MashburnWarren et al., 2010; Shanker and Federle, 2017; Underhill et al., 2019). Therefore comDE and $\operatorname{com} R$ will be interesting targets for further spatially resolved studies of gene expression in S. mutans biofilms.

Finally we note that the oral biofilm is a complex multispecies community in which $S$. mutans must compete with a number of commensal species (Bowen et al., 2018). These interactions can lead to highly localized inhibitory effects on competence behavior (Kaspar et al., 2020). Therefore, although the present work shows that the physical properties of the singlespecies biofilm do not themselves impose heterogeneity in competence behavior, localized interactions with commensal species may quite possibly impose spatial heterogeneity onto competence. Future studies probing $\operatorname{com} X$ activity in $S$. mutans may reveal correlation between competence and positioning relative to other bacterial colonies within a polymicrobial biofilm.

\section{DATA AVAILABILITY STATEMENT}

The datasets generated for this study are available on request to the corresponding author.

\section{AUTHOR CONTRIBUTIONS}

II and SH designed and performed experiments, analyzed and interpreted data, and wrote the manuscript. JK interpreted data, constructed bacterial strains, and edited the manuscript. All authors gave final approval to the manuscript and agreed to be accountable for all aspects of the work.

\section{FUNDING}

Funding support was provided under awards R01DE023339 and R01DE025237 from the National Institute of Dental and Craniofacial Research. Confocal microscopy was supported by the NIH Shared Instrumentation grant 1S10OD020026 to University of Florida (Dr. Habibeh Khoshbouei).

\section{ACKNOWLEDGMENTS}

We acknowledge microscopy assistance provided by Doug Smith of the UF Cell and Tissue Analysis Core, as well as discussions with Prof. Robert A. Burne and Dr. Robert C. Shields.

\section{SUPPLEMENTARY MATERIAL}

The Supplementary Material for this article can be found online at: https://www.frontiersin.org/articles/10.3389/fmicb.2020. 627992/full\#supplementary-material 


\section{REFERENCES}

Ahn, S.-J., and Burne, R. A. (2007). Effects of oxygen on biofilm formation and the AtlA autolysin of Streptococcus mutans. J. Bacteriol. 189, 6293-6302. doi: 10.1128/JB.00546-07

Ahn, S.-J., Lemos, J. A. C., and Burne, R. A. (2005). Role of HtrA in growth and competence of Streptococcus mutans UA159. J. Bacteriol. 187, 3028-3038. doi: 10.1128/JB.187.9.3028-3038.2005

Ahn, S.-J., Wen, Z. T., and Burne, R. A. (2006). Multilevel control of competence development and stress tolerance in Streptococcus mutans UA159. Infect. Immun. 74, 1631-1642. doi: 10.1128/IAI.74.3.1631-1642.2006

Aspiras, M., Ellen, R., and Cvitkovitch, D. (2004). ComX activity of Streptococcus mutans growing in biofilms. FEMS Microbiol. Lett. 238, 167-174. doi: 10.1111/ j.1574-6968.2004.tb09752.x

Bowen, W. H., Burne, R. A., Wu, H., and Koo, H. (2018). Oral biofilms: pathogens, matrix, and polymicrobial interactions in microenvironments. Trends Microbiol. 26, 229-242. doi: 10.1016/j.tim.2017.09.008

Branda, S. S., Vik, Å, Friedman, L., and Kolter, R. (2005). Biofilms: the matrix revisited. Trends Microbiol. 13, 20-26. doi: 10.1016/j.tim.2004.11.006

Cvitkovitch, D. G. (2001). Genetic competence and transformation in oral Streptococci. Crit. Rev. Oral Biol. Med. 12, 217-243. doi: 10.1177/104544110 10120030201

Dazzo, F. B. (2012). CMEIAS-aided microscopy of the spatial ecology of individual bacterial interactions involving cell-to-cell communication within biofilms. Sensors 12, 7047-7062. doi: 10.3390/s120607047

Dazzo, F., Klemmer, K., Chandler, R., and Yanni, Y. (2013). In Situ ecophysiology of microbial biofilm communities analyzed by CMEIAS computer-assisted microscopy at single-cell resolution. Diversity 5, 426-460. doi: 10.3390/ d5030426

De Furio, M., Ahn, S. J., Burne, R. A., and Hagen, S. J. (2017). Oxidative stressors modify the response of Streptococcus mutans to its competence signal peptides. Appl. Environ. Microbiol. 83:e01345-17. doi: 10.1128/AEM.013 45-17

Decho, A. W., Norman, R. S., and Visscher, P. T. (2010). Quorum sensing in natural environments: emerging views from microbial mats. Trends Microbiol. 18, 73-80. doi: 10.1016/j.tim.2009.12.008

Decker, E.-M., Klein, C., Schwindt, D., and von Ohle, C. (2014). Metabolic activity of Streptococcus mutans biofilms and gene expression during exposure to xylitol and sucrose. Int. J. Oral Sci. 6, 195-204. doi: 10.1038/ijos.2014.38

Dixon, P. M. (2013). "Nearest neighbor methods based in part on the article 'Nearest neighbor methods"' in Encyclopedia of Environmetrics, eds A.-H. ElShaarawi and W. Piegorsch (Chichester: John Wiley \& Sons Ltd), doi: 10.1002/ 9780470057339.van007.pub2

Ferrell, J. E. (2002). Self-perpetuating states in signal transduction: positive feedback, double-negative feedback and bistability. Curr. Opin. Cell Biol. 14, 140-148. doi: 10.1016/S0955-0674(02)00314-9

Fontaine, L., Wahl, A., Fléchard, M., Mignolet, J., and Hols, P. (2015). Regulation of competence for natural transformation in Streptococci. Infect. Genet. Evol. 33, 343-360. doi: 10.1016/j.meegid.2014.09.010

Gantner, S., Schmid, M., Dürr, C., Schuhegger, R., Steidle, A., Hutzler, P., et al. (2006). In situ quantitation of the spatial scale of calling distances and population density-independent $\mathrm{N}$-acylhomoserine lactone-mediated communication by rhizobacteria colonized on plant roots. FEMS Microbiol. Ecol. 56, 188-194. doi: 10.1111/j.1574-6941.2005.00037.x

Guo, L., Hu, W., He, X., Lux, R., McLean, J., and Shi, W. (2013). Investigating acid production by Streptococcus mutans with a surface-displayed $\mathrm{pH}$-sensitive green fluorescent protein. PLoS One 8:e57182. doi: 10.1371/journal.pone. 0057182

Guo, Q., Ahn, S.-J., Kaspar, J., Zhou, X., and Burne, R. A. (2014). Growth phase and $\mathrm{pH}$ influence peptide signaling for competence development in Streptococcus mutans. J. Bacteriol. 196, 227-236. doi: 10.1128/JB.00995-13

Haase, P. (1995). Spatial pattern analysis in ecology based on Ripley's K-function: introduction and methods of edge correction. J. Veg. Sci. 6, 575-582. doi: $10.2307 / 3236356$

Hagen, S. J., and Son, M. (2017). Origins of heterogeneity in Streptococcus mutans competence: interpreting an environment-sensitive signaling pathway. Phys. Biol. 14:015001. doi: 10.1088/1478-3975/aa546c

Hart, J. W., Waigh, T. A., Lu, J. R., and Roberts, I. S. (2019). Microrheology and spatial heterogeneity of Staphylococcus aureus biofilms modulated by hydrodynamic shear and biofilm-degrading enzymes. Langmuir 35, 3553-3561. doi: 10.1021/acs.langmuir.8b04252

Hense, B. A., Kuttler, C., Müller, J., Rothballer, M., Hartmann, A., and Kreft, J.-U. (2007). Does efficiency sensing unify diffusion and quorum sensing? Nat. Rev. Microbiol. 5, 230-239. doi: 10.1038/nrmicro1600

Hunter, R. C., and Beveridge, T. J. (2005). Application of a $\mathrm{pH}$-sensitive fluoroprobe (C-SNARF-4) for $\mathrm{pH}$ microenvironment analysis in Pseudomonas aeruginosa biofilms. Appl. Environ. Microbiol. 71, 2501-2510. doi: 10.1128/ AEM.71.5.2501-2510.2005

Ishkov, I. P., Ahn, S.-J., Rice, K. C., and Hagen, S. J. (2020). Environmental triggers of $\operatorname{lrg}$ A expression in Streptococcus mutans. Front. Microbiol. 11:18. doi: $10.3389 /$ fmicb. 2020.00018

Islam, M. M., Chakraborty, M., Pandya, P., Al Masum, A., Gupta, N., and Mukhopadhyay, S. (2013). Binding of DNA with Rhodamine B: spectroscopic and molecular modeling studies. Dye. Pigm. 99, 412-422. doi: 10.1016/j.dyepig. 2013.05.028

Kaspar, J. R., Lee, K., Richard, B., Walker, A. R., and Burne, R. A. (2020). Direct interactions with commensal Streptococci modify intercellular communication behaviors of Streptococcus mutans. ISME J. doi: 10.1038/s41396-020-00789-7

Kaspar, J., Underhill, S. A. M., Shields, R. C., Reyes, A., Rosenzweig, S., Hagen, S. J., et al. (2017). Intercellular communication via the comX-inducing peptide (XIP) of Streptococcus mutans. J. Bacteriol. 199:e00404-17. doi: 10.1128/JB.00404-17

Kim, D., Barraza, J. P., Arthur, R. A., Hara, A., Lewis, K., Liu, Y., et al. (2020). Spatial mapping of polymicrobial communities reveals a precise biogeography associated with human dental caries. Proc. Natl. Acad. Sci. U.S.A. 117, 1237512386. doi: 10.1073/pnas.1919099117

Kindler, O., Pulkkinen, O., Cherstvy, A. G., and Metzler, R. (2019). Burst statistics in an early biofilm quorum sensing model: the role of spatial colony-growth heterogeneity. Sci. Rep. 9:12077. doi: 10.1038/s41598-019-48525-2

Kiskowski, M. A., Hancock, J. F., and Kenworthy, A. K. (2009). On the use of Ripley's K-function and its derivatives to analyze domain size. Biophys. J. 97, 1095-1103. doi: 10.1016/j.bpj.2009.05.039

Klein, M. I., Duarte, S., Xiao, J., Mitra, S., Foster, T. H., and Koo, H. (2009). Structural and molecular basis of the role of starch and sucrose in Streptococcus mutans biofilm development. Appl. Environ. Microbiol. 75, 837-841. doi: 10. 1128/AEM.01299-08

Koo, H., Falsetta, M. L., and Klein, M. I. (2013). The exopolysaccharide matrix. J. Dent. Res. 92, 1065-1073. doi: 10.1177/0022034513504218

Kreth, J., Hagerman, E., Tam, K., Merritt, J., Wong, D. T. W., Wu, B. M., et al. (2004). Quantitative analyses of Streptococcus mutans biofilms with quartz crystal microbalance, microjet impingement and confocal microscopy. Biofilms 1, 277-284. doi: 10.1017/S1479050504001516

Kreth, J., Merritt, J., Zhu, L., Shi, W., and Qi, F. (2006). Cell density- and ComE-dependent expression of a group of mutacin and mutacin-like genes in Streptococcus mutans. FEMS Microbiol. Lett. 265, 11-17. doi: 10.1111/j.15746968.2006.00459.x

LeBlanc, D. J., Lee, L. N., and Abu-Al-Jaibat, A. (1992). Molecular, genetic, and functional analysis of the basic replicon of pVA380-1, a plasmid of oral streptococcal origin. Plasmid 28, 130-145. doi: 10.1016/0147-619X(92)90044-B

Leme, A. F. P., Koo, H., Bellato, C. M., Bedi, G., and Cury, J. A. (2006). The role of sucrose in cariogenic dental biofilm formation-new insight. J. Dent. Res. 85, 878-887. doi: 10.1177/154405910608501002

Loesche, W. J. (1986). Role of Streptococcus mutans in human dental decay. Microbiol. Rev. 50, 353-380. doi: 10.1128/mr.50.4.353-380.1986

Marcotte, L., Therien-Aubin, H., Sandt, C., Barbeau, J., and Lafleur, M. (2004). Solute size effects on the diffusion in biofilms of Streptococcus mutans. Biofouling 20, 189-201. doi: 10.1080/08927010400 010494

Mashburn-Warren, L., Morrison, D. A., and Federle, M. J. (2010). A novel doubletryptophan peptide pheromone controls competence in Streptococcus spp. via an Rgg regulator. Mol. Microbiol. 78, 589-606. doi: 10.1111/j.1365-2958.2010. 07361.x

Moye, Z. D., Son, M., Rosa-Alberty, A. E., Zeng, L., Ahn, S.-J., Hagen, S. J., et al. (2016). Effects of carbohydrate source on genetic competence in Streptococcus mutans. Appl. Environ. Microbiol. 82, 4821-4834. doi: 10.1128/AEM.01205-16

Nakanishi, Y., Yamamoto, T., Obana, N., Toyofuku, M., Nomura, N., and Kaneko, A. (2018). Spatial distribution and chemical tolerance of Streptococcus mutans within dual-species cariogenic biofilms. Microbes Environ. 33, 455-458. doi: 10.1264/jsme2.ME18113 
Parsek, M. R., and Greenberg, E. P. (2005). Sociomicrobiology: the connections between quorum sensing and biofilms. Trends Microbiol. 13, 27-33. doi: 10 . 1016/j.tim.2004.11.007

Qi, F., Merritt, J., Lux, R., and Shi, W. (2004). Inactivation of the ciaH gene in Streptococcus mutans diminishes mutacin production and competence development, alters sucrose-dependent biofilm formation, and reduces stress tolerance. Infect. Immun. 72, 4895-4899. doi: 10.1128/IAI.72.8.4895-4899.2004

Ripley, B. D. (1976). The second-order analysis of stationary point processes. J. Appl. Probab. 13, 255-266. doi: 10.2307/3212829

Senadheera, D. B., Cordova, M., Ayala, E. A., Chavez de Paz, L. E., Singh, K., Downey, J. S., et al. (2012). Regulation of bacteriocin production and cell death by the VicRK signaling system in Streptococcus mutans. J. Bacteriol. 194, 1307-1316. doi: 10.1128/JB.06071-11

Senadheera, M. D., Guggenheim, B., Spatafora, G. A., Huang, Y.-C. C., Choi, J., Hung, D. C. I., et al. (2005). A VicRK signal transduction system in Streptococcus mutans affects $g t f B C D, g b p B$, and $f t f$ expression, biofilm formation, and genetic competence development. J. Bacteriol. 187, 4064-4076. doi: 10.1128/JB.187.12. 4064-4076.2005

Shanker, E., and Federle, M. (2017). Quorum sensing regulation of competence and bacteriocins in Streptococcus pneumoniae and mutans. Genes (Basel) 8:15. doi: 10.3390/genes8010015

Shields, R. C., and Burne, R. A. (2016). Growth of Streptococcus mutans in biofilms alters peptide signaling at the sub-population level. Front. Microbiol. 7:1075. doi: $10.3389 /$ fmicb. 2016.01075

Shields, R. C., Walker, A. R., Maricic, N., Chakraborty, B., Underhill, S. A. M., and Burne, R. A. (2020). Repurposing the Streptococcus mutans CRISPR-Cas9 system to understand essential gene function. PLOS Pathog. 16:e1008344. doi: 10.1371/journal.ppat.1008344

Shields, R. C., Kaspar, J. R., Lee, K., Underhill, S. A. M., and Burne, R. A. (2019). Fluorescence tools adapted for real-time monitoring of the behaviors of Streptococcus species. Appl. Environ. Microbiol. 85:e00620-19. doi: 10.1128/ AEM.00620-19

Son, M., Ahn, S.-J., Guo, Q., Burne, R. A., and Hagen, S. J. (2012). Microfluidic study of competence regulation in Streptococcus mutans: environmental inputs modulate bimodal and unimodal expression of comX. Mol. Microbiol. 86, 258-272. doi: 10.1111/j.1365-2958.2012.08187.x

Son, M., Kaspar, J., Ahn, S. J., Burne, R. A., and Hagen, S. J. (2018). Threshold regulation and stochasticity from the MecA/ClpCP proteolytic system in Streptococcus mutans competence. Mol. Microbiol. 110, 914-930. doi: 10.1111/ mmi.13992

Son, M., Shields, R. C., Ahn, S.-J., Burne, R. A., and Hagen, S. J. (2015). Bidirectional signaling in the competence regulatory pathway of Streptococcus mutans. FEMS Microbiol. Lett. 362:fnv159. doi: 10.1093/femsle/fnv159

Stewart, P. S. (2003). Diffusion in biofilms. J. Bacteriol. 185, 1485-1491. doi: 10. 1128/JB.185.5.1485-1491.2003
Stewart, P. S., and Franklin, M. J. (2008). Physiological heterogeneity in biofilms. Nat. Rev. Microbiol. 6, 199-210. doi: 10.1038/nrmicro1838

Takahashi, N., and Nyvad, B. (2011). The role of bacteria in the caries process. J. Dent. Res. 90, 294-303. doi: 10.1177/0022034510379602

Takenaka, S., Pitts, B., Trivedi, H. M., and Stewart, P. S. (2009). Diffusion of macromolecules in model oral biofilms. Appl. Environ. Microbiol. 75, 17501753. doi: 10.1128/AEM.02279-08

Terleckyj, B., Willett, N. P., and Shockman, G. D. (1975). Growth of several cariogenic strains of oral Streptococci in a chemically defined medium. Infect. Immun. 11, 649-655. doi: 10.1128/IAI.11.4.649-655.1975

Underhill, S. A. M., Shields, R. C., Burne, R. A., and Hagen, S. J. (2019). Carbohydrate and PepO control bimodality in competence development by Streptococcus mutans. Mol. Microbiol. 112, 1388-1402. doi: 10.1111/mmi.14367

van der Ploeg, J. R. (2005). Regulation of bacteriocin production in Streptococcus mutans by the quorum-sensing system required for development of genetic competence. J. Bacteriol. 187, 3980-3989. doi: 10.1128/JB.187.12.3980-3989. 2005

Watnick, P., and Kolter, R. (2000). Biofilm, city of microbes. J. Bacteriol. 182, 2675-2679. doi: 10.1128/JB.182.10.2675-2679.2000

Welin-Neilands, J., and Svensäter, G. (2007). Acid tolerance of biofilm cells of Streptococcus mutans. Appl. Environ. Microbiol. 73, 5633-5638.

Xiao, J., and Koo, H. (2010). Structural organization and dynamics of exopolysaccharide matrix and microcolonies formation by Streptococcus mutans in biofilms. J. Appl. Microbiol. 108, 2103-2113. doi: 10.1111/j.13652672.2009.04616.x

Xie, Z., Qi, F., and Merritt, J. (2013). Development of a tunable wide-range gene induction system useful for the study of streptococcal toxin-antitoxin systems. Appl. Environ. Microbiol. 79, 6375-6384. doi: 10.1128/AEM.02320-13

Yoshida, A., and Kuramitsu, H. K. (2002). Multiple Streptococcus mutans genes are involved in biofilm formation. Appl. Environ. Microbiol. 68, 6283-6291. doi: 10.1128/AEM.68.12.6283-6291.2002

Zhang, Z., Nadezhina, E., and Wilkinson, K. J. (2011). Quantifying diffusion in a biofilm of Streptococcus mutans. Antimicrob. Agents Chemother. 55, 1075-1081. doi: 10.1128/AAC.01329-10

Conflict of Interest: The authors declare that the research was conducted in the absence of any commercial or financial relationships that could be construed as a potential conflict of interest.

Copyright (c) 2021 Ishkov, Kaspar and Hagen. This is an open-access article distributed under the terms of the Creative Commons Attribution License (CC BY). The use, distribution or reproduction in other forums is permitted, provided the original author(s) and the copyright owner(s) are credited and that the original publication in this journal is cited, in accordance with accepted academic practice. No use, distribution or reproduction is permitted which does not comply with these terms. 